\title{
Study of Gender-based In-Hospital Mortality Difference in Patients with Acute Myocardial Infarction
}

\author{
NK Majumder ${ }^{1}$, MR Khan², Nupur Kar ${ }^{3}$, M Akhtaruzzaman $^{4}$, TA Choudhury ${ }^{5}$, MAtahar Ali6, GM Faruque ${ }^{7}$
}

\begin{abstract}
:
Background: In-hospital mortality in female patients with acute myocardial infarction (AMI) and factors affecting this may be different from those of their male counterpart. The aim of the current study was to compare the in-hospital mortality between female and male patients with AMI and to compare the differences in age, risk factors, treatment given and complications between them.
\end{abstract}

Methods: Total 200 nonrandomised patients with a definite diagnosis of AMI admittedover a period of one year (January 2008 - December 2008) were enrolled in the study, in which 100 female patients were considered as cases and 100 male patients as controls. Both groups were studied prospectively.Datawere collected in prefixed questionnaire and data sheet and were analysed using SPSS software.

Results: mean age of the female patients was significantly higher than that of their male counterpart (57.0 \pm 10.1 years and $53.3 \pm 10.3$ years respectively, $p=0.029$ ). Diabetes mellitus and hyperlipidemia were significantly higher in females than those in males $(39 \%$ vs $24 \%, p=0.022$ and $45 \%$ vs $32 \%, p=0.040$ respectively), while smoking was staggeringly higher among the males $(59 \%)$ compared to the females $(4 \%)(p<0.001)$.
However, no significant difference was observed between the groups in terms of hypertension $(p=0.666)$.Pre-hospital delay (more than 12 hours after onset of chest pain) was significantly higher in the female group than that in the male group $(72 \%$ vs $58 \%, p=0.038)$. Streptokinase was significantly underused in females $(15.6 \%)$ compared to that used in males $(32.2 \%)(p=0.011)$. The use of $b$-receptor blockerswas also significantly less in females than that in males $(63 \%$ vs $75 \%, p=0.046)$.Death was significantly higher in the females $(21 \%)$ than that in the males $(10 \%)$ $(p=0.032)$. Unstable angina, re-infarction and congestive heart failure were somewhat higher in the female subjects compared to their male counterparts (40\% vs $34 \%, 2 \%$ vs $1 \%$ and $32 \%$ vs $23 \%$ respectively) though the differences did not seem significant ( $p=0.380, p=0.561$ and $p=0.154$ respectively). Arrhythmias did not differ significantly between the groups ( $\left.p^{1}>0.05\right)$.

Conclusion: Female patients with AMI had significantly higher in-hospital mortality. Early hospitalization and optimal treatment are crucial to decrease mortality in female patients.

Key words: Myocardial Infarction, Gender, Mortality.

(Bangladesh Heart Journal 2017; 32(2) : 119-124)

Introduction:

Coronary heart disease (CHD) and specifically AMI are the most common causes of death among both males and females throughout the world.Although AMI affects males in greater numbers, the short-term outcomes for females are worse. It is still a major problem that in-hospital case fatality and morbidity rates in the post-infarction period are higher for females ${ }^{1}$.After AMI, a higher short-term mortality in females is documented ${ }^{2}$.

1. Associate Professor, Cardiology, Rajshahi Medical College, Rajshahi, Bangladesh.

2. Assistant Professor, Cardiology, Shaheed Suhrawardi Medical College, Dhaka, Bangladesh.

3. Associate Professor, Cardiology, National Institute of Cardiovascular Diseases, Dhaka, Bangladesh.

4. Junior Consultant, Cardiology, Upazilla Health Complex, Kahaloo, Bogra, Bangladesh.

5. Junior Consultant, Cardiology, 250 Beds Hospital, Moulavibazar, Bangladesh.

6. Professor, Cardiology, NICVD, Dhaka, Bangladesh.

7. Ex Professor, Cardiology, NICVD, Dhaka, Bangladesh.

Address of Correspondence: Dr. NK Majumder, Associate Professor, Department of Cardiology, Rajshahi Medical College, Rajshahi, Bangladesh. Cell: +8801712247751, E-mail: nkcardmed@gmail.com

DOI: http://dx.doi.org/10.3329/bhj.v32i2.36099

Copyright @ 2017 Bangladesh Cardiac Society. Published by Bangladesh Cardiac Society. This is an Open Access articles published under the Creative Commons Attribution-NonCommercial 4.0 International License (CC BY-NC). This license permits use, distribution and reproduction in any medium, provided the original work is properly cited and is not used for commercial purposes. 
In Bangladesh, in a 3 month follow up study after AMI, mortality was $36.3 \%$ in females compared to $19.4 \%$ in males $^{3}$. But factors influencing increased in-hospital and short-term mortality in females have not been studied in Bangladesh. Finding out the influencing factors of mortality is important for the development of appropriate measures to improve their clinical course and outcome. If these influencing factors could be managed earlier and properly, many female lives could be saved by taking effective measures and higher mortality rate in females would have been reduced.

Factors influencing increased in-hospital mortality in females observed in international studies may or may not be similar in our country. So, in the present study, In-hospital mortality rate between male and female patients with AMI was compared. In addition, factors influencing thegender-based in-hospital mortality differencewere assessed.

\section{Aims and objectives:}

General objective of this study was to compare the inhospital mortality between male and female patients with AMI. Specific objectives were to identify the influencing factors of in-hospital mortality in patients with AMI, to compare these between male and female patients and their role in predictingender-based mortality difference.

\section{Patients and methods:}

This prospective observational study was done in the department of Cardiology, National Institute of Cardiovascular Diseases (NICVD), Dhaka, Bangladesh during the period from January 2008 - December 2008. Total 200 nonrandomisedpatients with a definite diagnosis of AMI were enrolled in the study, in which 100 female patients were considered as cases and 100 male patients as controls. AMI patients presenting first time in the hospital within 24 hours of symptom onset were included in this study. AMI patients admitted after 24 hours of symptom onset and those with associated prior myocardial infarction, prior percutaneous coronary intervention $(\mathrm{PCl})$ or coronary artery bypass grafting (CABG) were excluded from the study. AMI was diagnosed according to Universal definition criteria 4 :Detection of rise and or fall of cardiac biomarkers (preferably troponin) with at least one value above the $99^{\text {th }}$ percentile of the upper reference limit (URL) together with evidence of myocardial ischemia with at least one of the following: 1)symptoms of ischemia 2)ECG changes indicative of new ischemia [new ST-T changes or new left bundle branch block (LBBB)] 3)development of pathological $Q$ waves in the ECG 4) imaging evidence of new loss of viable myocardial or new regional wall motion abnormality. In our laboratory setting, cut off value of Troponin I was 0.49 nanogram per milliliter $(\mathrm{ng} / \mathrm{mL})$.
Patients were treated according to 'Acute coronary syndrome guideline for management (2004)',Bangladesh Cardiac Society, Dhaka, Bangladesh ${ }^{5}$. In eligible cases, reperfusion therapy was given with streptokinase in those presenting within 12 hours of onset of chest pain. Other medications were used as per recommendations in guideline. Cardiac failure and other complications were managed accordingly. Patient's cardiac failure was assessed clinically according to Killip classification ${ }^{6}$ as follows:class (i) No heart failure: No signs of congestive heart failure, class(ii) Heart failure: $\mathrm{S}_{3}$ gallop and bibasilar rales, class(iii) Severe heart failure: Frank pulmonary edema, class(iv) Cardiogenic shock: Hypotension (systolic pressure of $90 \mathrm{~mm}$. Hg or less) and evidence of peripheral vasoconstriction such as oliguria, cyanosis and diaphoresis.

Data were analyzed using SPSS (Statistical Package for Social Sciences) version. The test statistics employed to analyze the data were unpaired t-test, chi-square test and Fisher's exact test. For each analytical test, $p<0.05$ was considered significant. Appropriate ethical implications were maintained.

\section{Results:}

Age distribution of the study population is shown in table I. Most of the patients were in 41-60 years age range in both groups (females $63 \%$ vs males $67 \%$ ). Mean age was found $57.0 \pm 10.1$ in females and $53.3 \pm 10.3$ years in male $(p=0.029)$.

Females and males were different in major risk factor profile which is shown in table II. Diabetes Mellitus(DM), Hypertension (HTN), smoking and Dyslipidemia were 39\% vs $24 \%, 42 \%$ vs $39 \%, 4 \%$ vs $59 \%$, and $45 \%$ vs $32 \%$ in females and males respectively. Differences were statistically significant in terms of DM, smoking and dyslipidemia $(p<0.05)$ but not in HTN.

Prehospital delay was more in female patients than males (72\% vs $58 \%, p=0.038)$ as shown in table III.

Streptokinase and beta blockers were also underused in females compared to males ( $15.6 \%$ vs $32.2 \%, p=0.011$ and $63 \%$ vs $75 \%, p=0.046$ respectively) which are shown in tables IV and V.

Table VI shows that there was significant higher in-hospital mortality in females in comparison to males ( $21 \%$ vs $10 \%$, $\mathrm{p}=0.032$ ).

Table VII shows complications which reveals that Congestive heart failure, Unstable angina and re-infarction were more in females than males though the differences are not significant statistically. 
Table-I

Age distribution of the study population $(\mathrm{N}=200)$

\begin{tabular}{|c|c|c|c|c|c|}
\hline \multirow[t]{3}{*}{ Age group in year } & \multicolumn{4}{|c|}{ Group } & \multirow[t]{3}{*}{ p-value } \\
\hline & \multicolumn{2}{|c|}{ Female $(n=100)$} & \multicolumn{2}{|c|}{ Male $(\mathrm{N}=100)$} & \\
\hline & $\mathrm{N}$ & $\%$ & $\mathrm{~N}$ & $\%$ & \\
\hline$\overline{31-40}$ & 6 & 6.0 & 14 & 14.0 & \\
\hline $41-50$ & 27 & 27.0 & 28 & 28.0 & \\
\hline $51-60$ & 36 & 36.0 & 39 & 39.0 & \\
\hline $61-70$ & 24 & 24.0 & 15 & 15.0 & \\
\hline$>70$ & 7 & 7.0 & 4 & 4.0 & \\
\hline Mean age $\pm S D$ (years) & \multicolumn{2}{|c|}{$57.0 \pm 10.1$} & \multicolumn{2}{|c|}{$53.3 \pm 10.3$} & $0.029^{*}$ \\
\hline
\end{tabular}

Data were analyzed using unpaired t-test

* Significant at the level of $p$-value $<0.05$

Table-II

Distribution of the study population by risk factors $(N=200)$

\begin{tabular}{|c|c|c|c|c|c|c|}
\hline \multirow[t]{3}{*}{ Risk factors } & & \multicolumn{4}{|c|}{ Group } & \multirow[t]{3}{*}{ p-value } \\
\hline & & \multicolumn{2}{|c|}{ Female $(n=100)$} & \multicolumn{2}{|c|}{ Male $(n=100)$} & \\
\hline & & No. & $\%$ & No. & $\%$ & \\
\hline \multirow[t]{2}{*}{ DM } & Yes & 39 & 39.0 & 24 & 24.0 & $0.022^{*}$ \\
\hline & No & 61 & 61.0 & 76 & 76.0 & \\
\hline \multirow[t]{2}{*}{ Hypertension } & Yes & 42 & 42.0 & 39 & 39.0 & $0.666^{\mathrm{NS}}$ \\
\hline & No & 58 & 58.0 & 61 & 61.0 & \\
\hline \multirow[t]{2}{*}{ Smoking } & Yes & 4 & 4.0 & 59 & 59.0 & $<0.001^{* * *}$ \\
\hline & No & 96 & 96.0 & 41 & 41.0 & \\
\hline \multirow[t]{2}{*}{ Hyperlipidemia } & Yes & 45 & 45.0 & 32 & 32.0 & $0.040^{*}$ \\
\hline & No & 55 & 55.0 & 68 & 68.0 & \\
\hline
\end{tabular}

Data were analyzed using Chi-square test

* Significant at the level of $p$-value $<0.05$

*** Significant at the level of $p$-value $<0.001$

NS- Not significant $(p>0.05)$

Table-III

Distribution of the study population $(N=200)$ by pre-hospital delay.

\begin{tabular}{|c|c|c|c|c|c|}
\hline \multirow{3}{*}{$\begin{array}{l}\text { Time between onset of } \\
\text { chest pain and hospital arrival }\end{array}$} & \multicolumn{4}{|c|}{ Group } & \multirow[t]{3}{*}{$\mathrm{p}$-value } \\
\hline & \multicolumn{2}{|c|}{ Female $(n=100)$} & \multicolumn{2}{|c|}{ Male $(n=100)$} & \\
\hline & no. & $\%$ & no. & $\%$ & \\
\hline$>12$ hours & 72 & 72.0 & 58 & 58.0 & $0.038^{*}$ \\
\hline$<12$ hours & 28 & 28.0 & 42 & 42.0 & \\
\hline
\end{tabular}

Date were analyzed using Chi-square test

*Significant at the level of $p$-value $<0.05$

Table-IV

Distribution of the study Subjects by the use of streptokinase ( $N=200)$. (Used only in STEMI patients).

\begin{tabular}{|c|c|c|c|c|c|}
\hline \multirow[t]{3}{*}{ Use of streptokinase } & \multicolumn{4}{|c|}{ Group } & \multirow[t]{3}{*}{ p-value } \\
\hline & \multicolumn{2}{|c|}{ Female $(\mathrm{n}=88)$} & \multicolumn{2}{|c|}{ Male $(\mathrm{n}=90)$} & \\
\hline & No. & $\%$ & No. & $\%$ & \\
\hline Used & 14 & 15.6 & 29 & 32.2 & $0.011^{*}$ \\
\hline Not used & 74 & 84.1 & 61 & 67.8 & \\
\hline
\end{tabular}

Data were analyzed using Chi-square test

* Significant at the level of $p$-value $<0.05$

STEMI-ST-segment-elevation myocardial infarction 
Table-V

Comparison of use of â-blockers between males and females $(N=200)$

\begin{tabular}{|c|c|c|c|c|c|}
\hline \multirow[t]{3}{*}{$\beta$-receptor blockers } & \multicolumn{4}{|c|}{ Group } & \multirow[t]{3}{*}{$p$-value } \\
\hline & \multicolumn{2}{|c|}{ Female $(n=100)$} & \multicolumn{2}{|c|}{$\operatorname{Male}(n=100)$} & \\
\hline & No. & $\%$ & No. & $\%$ & \\
\hline Used & 63 & 63.0 & 75 & 75.0 & $0.046^{*}$ \\
\hline Not used & 37 & 37.0 & 25 & 25.0 & \\
\hline
\end{tabular}

Data were analysed using Chi-square test

* significant at the level of $p$-value $<0.05$

Table-VI

Comparison of in-hospital mortality between the groups in the study population $(N=200)$

\begin{tabular}{|c|c|c|c|c|c|}
\hline \multirow[t]{3}{*}{ Outcome variable } & \multicolumn{4}{|c|}{ Group } & \multirow[t]{3}{*}{$p$-value } \\
\hline & \multicolumn{2}{|c|}{ Female $(n=100)$} & \multicolumn{2}{|c|}{ Male $(\mathrm{N}=100)$} & \\
\hline & No. & $\%$ & No. & $\%$ & \\
\hline Death & 21 & 21.0 & 10 & 10.0 & $0.032^{*}$ \\
\hline
\end{tabular}

Data were analysed using Chi-square test

* Significant at the level of p-Value $<0.05$

Table-VII

Distribution of study population by complications $(N=200)$

\begin{tabular}{|c|c|c|c|c|c|}
\hline \multirow[t]{3}{*}{ Variable } & \multicolumn{4}{|c|}{ Group } & \multirow[t]{3}{*}{ p-value } \\
\hline & \multicolumn{2}{|c|}{ Female $(n=100)$} & \multicolumn{2}{|c|}{ Male $(n=100)$} & \\
\hline & No. & $\%$ & No. & $\%$ & \\
\hline Congestive heart failure\# & 32 & 32.0 & 23 & 23.0 & $0.154^{N S}$ \\
\hline Unstable angina\# & 40 & 40.0 & 34 & 34.0 & $0.380^{N S}$ \\
\hline Re-infarction & 2 & 2.0 & 1 & 1.0 & $0.561^{\mathrm{NS}}$ \\
\hline Atrial fibrillation & 1 & 1.0 & 1 & 1.0 & $0.951^{N S}$ \\
\hline Supraventricular tachycardiađ & 1 & 1.0 & 2 & 2.0 & $0.864^{\mathrm{NS}}$ \\
\hline Ventricular tachycardiaף & 5 & 5.0 & 3 & 3.0 & $0.571^{N S}$ \\
\hline Ventricular fibrillationף & 7 & 7.0 & 5 & 5.0 & $0.718^{\mathrm{NS}}$ \\
\hline Av block(High degree $) \# 2^{\text {nd }}$ degree $3^{\text {rd }}$ degree & 12210 & 12.02.010.0 & 1046 & 10.04.06.0 & $0.811^{N S}$ \\
\hline
\end{tabular}

\# Data were analysed using Chi-square test

II Data were analysed with the help of Fisher's Exact Test

NS-Not significant $(p>0.05)$

\section{Discussion:}

Alfredssonet $\mathrm{al}^{2}$ mentioned that females sustaining AMI have a higher mortality than males. In Bangladesh perspective, we tried to explore in-hospital mortality difference between female and male patients with AMI and also to assess factors influencing this gender difference.In the present study, mean age of females was significantly higher than that of their male counterpart $(57.0 \pm 10.1$ years and $53.3 \pm 10.3$ years respectively, $p=0.029$ ). Momenuzzaman ${ }^{7}$ found a similar age distribution with respect to sex. The higher age incidence of ischemic heart diseases in female patients explains the fact that reproductive hormones before menopause offers protection against ischemic heart diseases, which is markedly reduced at menopause due to hormonal imbalance rendering them more vulnerable to ischaemic heart diseases ${ }^{8}$.Regarding risk factors,smoking was strikingly higher among males (59\%) compared to the females $(4 \%)(p<0.001)$. Similar smoking behaviour was observed in the studies conducted by others. 7,9,10 Diabetes mellitus was considerably higher in female patients (39\%) than that in male patients $(24 \%)$ which is consistent with Gottlieb et $\mathrm{al}^{9}$ and Jiang et $\mathrm{al}^{10}$. Momenuzzaman ${ }^{7}$ did not observe any 
sex differential in terms of diabetes mellitus, while Hanratty et al ${ }^{11}$ found a low prevalence of diabetes mellitus in both sexes (female $16 \%$ vs male $11 \%$ ). Regarding hypertension, no significant difference was observed between the groups (female $42 \%$, male $39 \%, p=0.666$ ) bearing consistency with findings of Momenuzzma ${ }^{7}$. However, the findings differ from those reported by Gottlieb et al ${ }^{9}$ and Jiang et $\mathrm{al}^{10}$ who found a significantly higher prevalence of hypertension in females compared to males.Females had a higher incidence of hyperlipidemia as opposed to males ( $45 \%$ vs $32 \%$, $p=0.040$ ). Similar results were also reported by others. ${ }^{9,10,12}$

Regarding treatment with reperfusion, in our series, we used Streptokinase for reperfusion therapy within 12 hours of symptom onset in cases of eligible STEMI patients. Streptokinase was significantly underused in females $(15.6 \%)$ compared to males $(32.2 \%)(p=0.011)$.Underuse of reperfusion therapy was also reported in other studies. ${ }^{7,10,13}$ The underuse of reperfusion therapy in our female patients may be explained by higher frequency of prehospital delay ( $>12$ hours) in females $(72 \%)$ compared to their male counterpart $(58 \%)(p=0.038)$. Nag et $a^{16}$ also explained delayed arrival as a cause of underuse of Streptokinase. Comparison of use ofâ-blockers showed it was underused in females $(63 \%)$ compared to males $(75 \%)$ which is statistically significant $(p=0.046)$. This finding is consistent with previous reports. ${ }^{9,10,12-15}$ The significant underuse of â-blockers in female patients in our study may be explained by the fact that more females had diabetes mellitus and congestive heart failure. International data support the fact that despite recommendations in favour of use of â-blockers, these are still underused in post-infarct patients, at the expense of many lives lost ${ }^{17}$.

Primary endpoint of our study was in-hospital death and secondary endpoints were unstable angina pectoris (early post $\mathrm{Ml}$ angina), re-infarction and congestive heart failure and arrhythmias. Our study results showed that despite all necessary treatments females had $21 \%$ in-hospital mortality compared to $10 \%$ in males. The difference is significant $(p=0.032)$.Similar results were observed by Hossain et al ${ }^{3}$ and others. ${ }^{7,10}$ Several other studies ${ }^{11,13,14}$ conducted around different parts of the world also reported higher in- hospital mortality in females than in males.Analysisof complications showed that in our series, Killip class III or more of cardiac failure was found in $14 \%$ females and $7 \%$ males. Our findings are in accordance with those found byjiang et $\mathrm{al}^{10}$ andVaccarinoet $\mathrm{al}^{14}$. These findings correlate with increased mortality in females, as Killip class of cardiac failure I through IV predicts hospital mortality by $6 \%, 17 \%$, $38 \%$ and $81 \%$ respectively 6 .

\section{Study Limitation:}

This study had several limitations. The followings deserve mention:

Firstly, the study sample was taken consecutively (nonrandomly) which might have affected the outcome of study.

Secondly, the sample size was relatively small as needed to predict the gender difference in mortality in patients of AMl.

Thirdly,risk factor profile is lacking in data of positive family history ofischaemic heart disease (IHD). Ambiguous history andlack of relevant documentary papers led us to this limitation.

Finally, the study did not have the scope to include the information of the patients of AMI who died on the way to reaching hospital, which might have resulted in an underestimation of the mortality rates in patients with AMI.

\section{Conclusion:}

From the findings of the study and discussion thereof it could obviously be concluded that females are more likely to die of acute myocardial infarction than males with same disease. Females are generally older than their male counterpart, arrive later in hospital after symptom onset and have higher Killip class (e"III) of cardiac failure. The study also reveals that females have a higher prevalence of major risk factors for ischemic heart diseases except smoking. Streptokinase and â-blockers are less used in females than in males. Recognizing the mortality difference between females and males with acute myocardial infarction is of paramount clinical significance, for females need optimal treatment like males.

\section{References:}

1. Karcioglu O, Aslan BU, Aslan O. Gender differences in the management $\&$ survival of patients with acute myocardial infarction. Eur J Intern Med. 2002; 13: $474-479$.

2. Alfredsson J, Stenestrand U, Wallentin L, Swahn E. Gender differences in management and outcome in Non-ST elevation acute coronary syndrome. Heart 2007; 93:1357-1362.

3. Hossain M, Dhar SC, Zaher A. Clinical outcome of acute $\mathrm{Ml}$ cases in the hospital and for three months thereafter followed prospectively. Bangladesh Heart Journal 1993; 8(2):31-35.

4. Thygesesn K, Alpert JS and White HD on behalf of the Joint ESC/ACCF/AHA/WHF Task Force for the Redefinition of Myocardial Infarction. Universal 
definition of myocardial infarction. Expert consensus document. Eur Heart J. 2007; 28:2525-2538.

5. Acute Coronary Syndrome: Guideline for Management 2004, Bangladesh Cardiac Society, Dhaka, Bangladesh.

6. Killip T, Kimball JT. Treatment of myocardial infarction in a coronary care unit. A two year experience with 250 patients. Am J Cardiol 1967;20:457-464.

7. Momenuzzaman NAM. A comparative study of risk factors and complications of acute myocardial infarction in females with those in males. Thesis (MD Cardiology), National Institute of Cardiovascular Diseases, Dhaka, Bangladesh. 1996.

8. Newby LK, Douglas PS. Cardiovascular disease in women. In:LibbyP,Bonow RO, Mann DL, Zipes DP, editors. Braunwald's Heart Disease. 8th ed. Philadelphia: Saunders; 2008. p. 1955-1956.

9. Gottlieb S, Harpaz D, Shotan A, Boyko V, Leor J, Cohen $M$, et al. Sex differences in management and outcome after acute myocardial infarction in the1990s: a prospective observational community based study. Circulation 2000; 102:2484-2490.

10. Jiang SL, Ji XP, Zhao YX, Wang XR, Song ZF, Ge ZM et al. Predictors of In-hospital mortality difference between male and female patients with acute myocardial infarction. Am J Cardiol 2006; 98: 10001003.
11. Hanratty B, Lawlor DA, Robinson MB, Sapsford RJ, Greenwood D. Sex differences in factors treament and mortality after acute myocardial infarction: an observational study. J Epidemiol Community Health 2000; 54: 912-916.

12. Kanamasa K, Ischikawa K, Hayashi T, Hoshida S, Yamada Y, Kawarabayashi T, et al. Increased cardiac mortality in women compared with men in patients with acute myocardial infarction. Intern Med 2004; 43(10): 911-918.

13. Heer T, Schiele R, Schneider S, GittAK, Wienbergen $\mathrm{H}$, Gottwi KM et al. Gender differences in Acute Myocardial Infarction in the Era of Reperfusion. . Am J Cardiol 2002; 89:511-17.

14. Vaccarino V, Parsons L, Every NR, Barron HV, Krumholz HM. Sex based differences in early mortality after myocardial infarction. N Engl. J Med 1999; 341:217-225

15. Lundberg V, WiKstrom B, Bostrom S, Asplund K. Exploring sex difference in case fatality in acute myocardial infarction or coronary death event in the northern Sweden MONICA project. Journal of Internal Medicine 2002; 251:235-244.

16. Nag DC, Bashar MA, Bari S, Bhuiyan AH, Alam S, Hossain MB et al. Study of STEMI in coronary care unit of Dhaka National Medical College Hospital. Chest \& Heart Journal 2007; 31(1):41-46.

17. Opie LH.â-blocking agents. In:Opie LH, Gersh BJ, Mardikar H, editors. Drugs for the Heart. South Asia ed.New Delhi: Elsevier; 2014. p. 1-38. 